\title{
Perspectives from students
}

Lara Isbel \& Judy Robertson

We wanted EqualBITE to have contributions from people across the University. Our recipe-writing workshops, held on each of the campuses, tended to attract staff members (usually women) but seldom students. This article describes some false starts in involving students in EqualBITE, and explains how the student photographs and illustrations contained in the volume were gathered.

Our aim in gathering content for the book was different from the aims of an academic research project. Where a research project might focus on the representativeness of the views, or whether the sampling strategy was effective, our goal was to give students the opportunity to contribute to the book if they wanted to, and in a way which they found appealing.

We felt it was important to represent the experiences and views of students on the topics which mattered to them, as often gender equality efforts in universities (such as Athena SWAN) have focused on the proportions of female students at various levels, without taking into account what the culture is like. Although Athena SWAN submissions now often contain survey data on staff work-life satisfaction, the analogous data for students has not been required. Our goal was to give the reader some insight into what it is like to be a women student at the University of Edinburgh.

\section{An open survey}

When we realised we needed to look for alternative opportunities to encourage students to contribute to the project, we asked the Edinburgh University Students' 
Association for their help in reaching the student body. They believed that the recipe format was likely off-putting to students, and suggested that they get in touch with students on our behalf with a more concise way to gather views, such as a short online survey question. The editorial team spent various frustrating meetings trying to phrase a question.

The Students' Association staff kindly forwarded our questions to relevant student societies, but on receiving no response at all, they circulated a very brief survey to all the students in the University (around 38,00o people). We asked the students how stereotypes about gender affected their university experience, what might minimise this effect, and asked if there was anything else they would like to say about gender equality in the University.

We got a grand total of four responses. While the very small number of people taking part is far too small to be a representative sample, we wanted to include their opinions, particularly as the variety of experiences ranged quite broadly.

Our first response was from a male undergraduate in the Medical School who said gender stereotypes had 'not at all' affected his University experience. He added:

Increasing pressure from the professionally offended make me worried that being a straight white male in itself is beginning to become risky. I study medicine. We have a gender inequality in med school group of females who like to complain about certain things. $60 \%$ of med school is female. If I started a male gender inequality in med school committee for that reason (and others) I would be vilified. The current level of hypocrisy is ridiculous.

An undergraduate student in the School of Chemistry who described their gender as binary also felt that gender stereotypes had minimal impact:
They don't. I ignore them [gender stereotypes] and get on with my life. It's pretty equal, but we don't need parity for the sake of it.

A non-binary (female), undergraduate student, School of Philosophy,

Psychology and Language Sciences had a different experience.

The boys/men in the class take up a lot of time asking questions to the lecturer, and are not suggested to wait until another time or to continue the talk elsewhere. Girls/women are often suggested to stop talking or simply don't get the chance to talk because the boys dominate the discussions.

I also feel that, because I am non-binary, less people will talk with me in classes, I don't feel that I am as included as other people are. I think teachers should be aware of the time they are giving up in the classes for discussion, and how they may distribute it unfairly based on gender.

I think it [the University] is generally good and progressive. It would be good to start having non-binary bathrooms, as I know this is something that many people would like.

Our last survey response was from a female undergraduate student in the School of Literatures, Languages and Cultures who reported a similar classroom experience:

In tutorials and seminars, even though women outnumber men in my classes, male students often manage to take over the conversation, or limit the input of female students who might not want to have to raise their voice to be heard.

To tackle this, she suggested:

Greater management by staff of conversation, focusing on inclusivity. 
This student also reported having to deal with challenging behaviour outside of class:

I have had various unpleasant experiences with male students outside of university time and offcampus in which I have been bullied, intimidated, or otherwise subjected to unwanted advances, physical contact and attention. The internal mechanisms for reporting this are inadequate. There is a culture on non-inclusivity among University of Edinburgh students, on class, gender, sexuality and ethnicity lines, and the University does not do enough to combat this. Students are ambassadors for the University and the University should take such inappropriate behaviour more seriously.

The issue of sexual harassment is considered in the articles that follow. For staff members who would like to improve their practice in these areas, the recipes on Creating a safe space for classroom discussions and Support for students who report sexual harassment or assault may be helpful. The Educated Pass recipe documents one of the University's projects which aims to give men educational opportunities.

\section{Discussions with gender and primary education students}

As the students did not have the time or inclination to reply to an online survey - and let's face it everyone's inbox is overflowing with online surveys - we decided to start discussions with students within academic classes.

One of the editors, Judy Robertson, visited the fourth-year Gender and Primary Education course at the Moray House School of Education (with the kind permission of the lecturer, Dr Ann MacDonald). It was particularly interesting to talk to student teachers about their view on gender equality, both because it is a female-dominated profession, and because primary school teachers have a powerful role in shaping children's attitudes which will in turn influence society in the future. It was the last class of the course, and the students were displaying posters of their ideas to help them draft an essay.

She started the session explaining about the book, and asked for the students' opinions about their experiences of gender equality at the University. When she asked the students "if you could change one thing at the University of Edinburgh relating to gender equality what would it be?" the students had nothing they wanted to share at that point although they agreed to write down their thoughts and return them later.

When the editor walked around the posters, and chatted to small groups of students, she found that they had plenty to say. They spoke about everyday sexism which they encountered on campus, in sports, in bars and in their workplaces. One student was frustrated because she felt her sport - cheerleading - is not recognised in the same way other sports are:

\section{We go to the competitions, making} history in the UK cheerleading scene, but the university don't really care about that. How often do you hear about what we've done? We're the most trophied sport/club in the University but how often do you hear that? Never... We win nationals every year and no one knows about that... It's so annoying when we go down there and we achieve so much and I come back up and I am so scared to tell someone. Also I am not allowed to get time off [from studying] to go to competitions because it is not a registered sport.

The status of cheerleading as a sport is in flux. Cheerleading has recently been given provisional recognition as a sport by the International Olympic Committee. The student above is referring to recognition by Sports Scotland and the University. 
Two of the written comments followed up on the theme of sports societies:

While there are policies in place, lad culture is still very prevalent in sports societies.

[the one thing I would change is] tackling "lad" banter within sports societies. There continues to be pervasive attitudes of male superiority and female objectification within some of the University's male sports clubs/teams.

Two of the students wrote that they thought it was important for the University to tackle the "lad" /"rape" culture, one emphasising that "girls should feel safe at uni".

The students mentioned how they felt comfortable on the School of Education campus (where a high proportion of the students are women) but that they felt less comfortable on the main campus because of what they described as the "lad culture".

They associated the problem with particular groups of students:

There's a lot of white upper class boys. Not solely. But that's quite a lot of what Edinburgh Uni is made up of.

One student said that:

If you go to [the student union] or the main library you can see it and like hear it [the lad culture] and if I go to the main library I feel like I should wear something nice and put on make-up. More so than if I came here because it is all girls here.

Another agreed, commenting that:

It's the whole male gaze thing. If you go to the main library, you feel very looked at.

They also discussed campaigns organised by the Students' Association relating to sexual harassment and assault, consent and alcohol. The students mentioned a rape in the park near the main university campus a few years ago, which to their minds had brought a lot of attention to the issue of sexual assault, and whether women should be advised to change their routes and behaviour in order to stay safe.

One student said that: "That campaign, No One Asks for It, it is fantastic" (see $A$ reflection on the University of Edinburgh's policy on sexual harassment) although the students were not convinced that the campaign had the necessary reach. They thought that students would benefit from education about sexual consent, particularly when alcohol is involved, but they were unsure what the student union was doing about this, or what approach would be effective in reaching the right student groups.

They thought that student unions in general should behave responsibly by refraining from selling alcohol at very low prices, one noting that: "I think our union is quite responsible about that".

The students spoke of double binds and contradictions they encountered in their social lives at the University and beyond. A male student brought up the contradiction between EUSA's active campaigning on equality issues (such as the campaign to provide genderneutral toilet facilities, an issue which the students supported) and an event run on Students' Association premises in which:

It was interesting that at the Saturday night club they were choosing to have shot girls who go around selling shots [of alcohol]. They wear high heels and are very very feminine - emphasised femininity. It was interesting that with the student union being seen as progressive that still on a club night they had people doing that.

When asked whether he would be more likely or less likely to buy alcohol when it was sold in such a way, he 
replied that it didn't make a difference. The Edinburgh University Students' Association stated that: "We have acted swiftly to make sure that this will not happen in Students' Association venues in the future, in line with our mission and values" when the editorial team brought this incident to their attention, further noting that the issue has been directly brought by their members previously.

There was a double bind related to their perception of men's inconsistent attitudes to women and alcohol:

[when I am] around other sports teams (predominantly male), ... I get called "boring" because I am not out, smashed, all the time. Especially on social nights even if I still go to the club, have a fab night, the fact that I am not drunk - they don't like it.

Another student agreed:

If a girl gets really drunk, then boys will say she can't handle it. Or she is a ladette, a bingedrinking girl. You can't win.

Expectation about women students' appearance caused them stress. This manifested in generalised expectations from one's peer group:

We were talking about getting dressed up for a night out and how you can't go out on a night out wearing leggings and a jumper. As much as you'd love to, but it is so frowned upon. Even if you can't be bothered you are wearing the highest heels in the world and your feet are killing you, you have to do it.

But as well as social pressure, some of the students had experienced pressures about their appearance from their employers. The women had been asked to provide full body and face photographs with their job applications forms, had been required to wear extra tight T-shirts and shorts, and had been requested to change aspects of their appearance at work, including removing their spectacles. One student explained about the exacting and contradictory instructions of her boss:

You have to wear your hair down and wear heels. But then he was like "you're really tall, don't look too tall".

Another student was sent home from work for not wearing make-up in her role as a hostess at a bar. As she phrased it:

I apparently wasn't pretty enough so I got sent home.

She chose not to return to her job because:

I am not going to portray myself as someone different. You hired me for me! I wasn't any more made-up when you hired me.

The students finished this section of the conversation by saying:

There is so much pressure, I would say. It's awful.

Girls have the short straw don't they?

On a more positive note, the students' posters about gender and teaching in primary schools demonstrated that this sample of student teachers were thoughtfully aware of their responsibilities in teaching the next generation about redressing gender inequalities and reducing discrimination relating to sexual orientation and gender identity.

In summary, while none of the School of Education students had experienced gender inequality or discrimination during their studies, they described how they routinely contended with gendered expectations about their behaviour or appearance in social settings, and felt uncomfortable in some parts of the campus because of this.

The cases where the students had been told to dress in a particular way by their male employers are troubling; it would be useful to consider whether a joint campaign between the University careers service and 
the Students' Association could alleviate this. It is often necessary for students to work to financially support their studies; they should not be subject to male whims about their appearance while they do so.

\section{The power of visual art}

Visiting the School of Education students was very valuable to help the team to understand what it is like to be a woman student at the University of Edinburgh today. We were still no further forward in collecting student-generated content for the book. As the written word did not appear to be appealing for students, we decided to be more flexible about content type: what about visual art? This would enable students to be creative and expressive, and could help us to gather evocative experiences to give the reader insight into aspects of the students' lives. We took two approaches to this: one was to visit another class to ask our art students to draw their experiences, and the other was to respond to the serendipitous opportunity presented by a photographic exhibition organised by Edinburgh University Students' Association. 


\section{Illustrations by the Edinburgh College of Art students}

Following the suggestion of Chris Belous, the Women's Officer for Edinburgh University Students' Association, we decided to include some illustrations drawn by students at the Edinburgh College of Art (ECA). We got in touch with Dr Harvey Dingwall, a lecturer in Illustration, to ask if we might visit his class to work with the students, to which he kindly agreed. We spent two hours working with his third-year class, discussing the students' experiences of gender inequality, at the University and in their lives more widely. In common with the students in the School of Education, at the start of the discussion, many of the students did not identify that they had experienced gender inequality. They spoke very positively of their safe and supportive learning environment within the ECA, and indeed the mutually respectful atmosphere during the discussion was a testament to the rapport between the class and the lecturer. However, after further discussion in small groups and through initial sketching, the students began to talk of their wider experiences with the University facilities (such as the need for gender-neutral toilets), University gym, clubs and the city in general. A story which we found particularly striking about the culture in a University bar is illustrated below. We learned, to our perplexity, that it is the habit of some (mostly male) students to throw their nearly, but not quite, empty beer bottles on to the heads of fellow (mostly female) patrons, soaking them.

The students then had the opportunity to work on their drawings further in their own time, and could choose whether to submit them to the editors for potential inclusion in this book. All of the drawings were of a high standard, and the editorial team selected those which were relevant to academic or social life at the University. All those who submitted a drawing received a token to spend at a local art shop.

You can see these wonderful images below. 

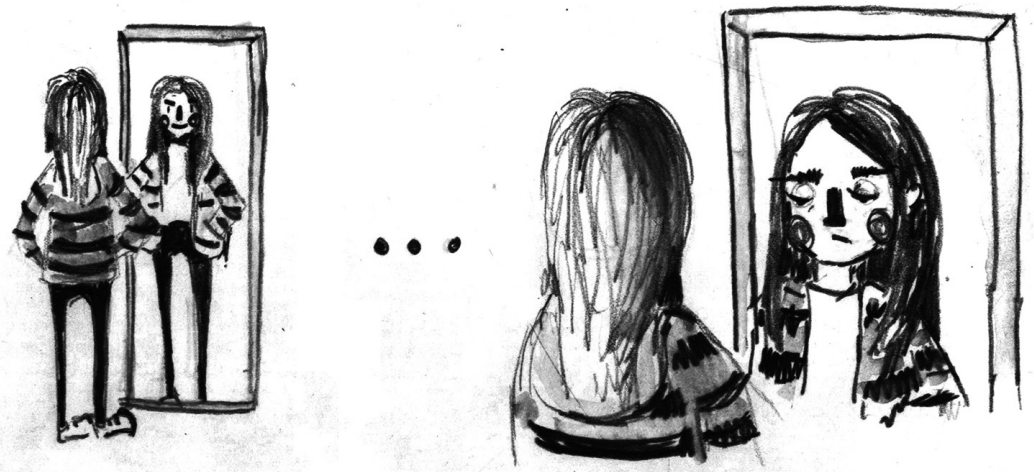

I was taught in school that if I didn't live up to the standards of my male classmates, then I wasn't owed any respect.

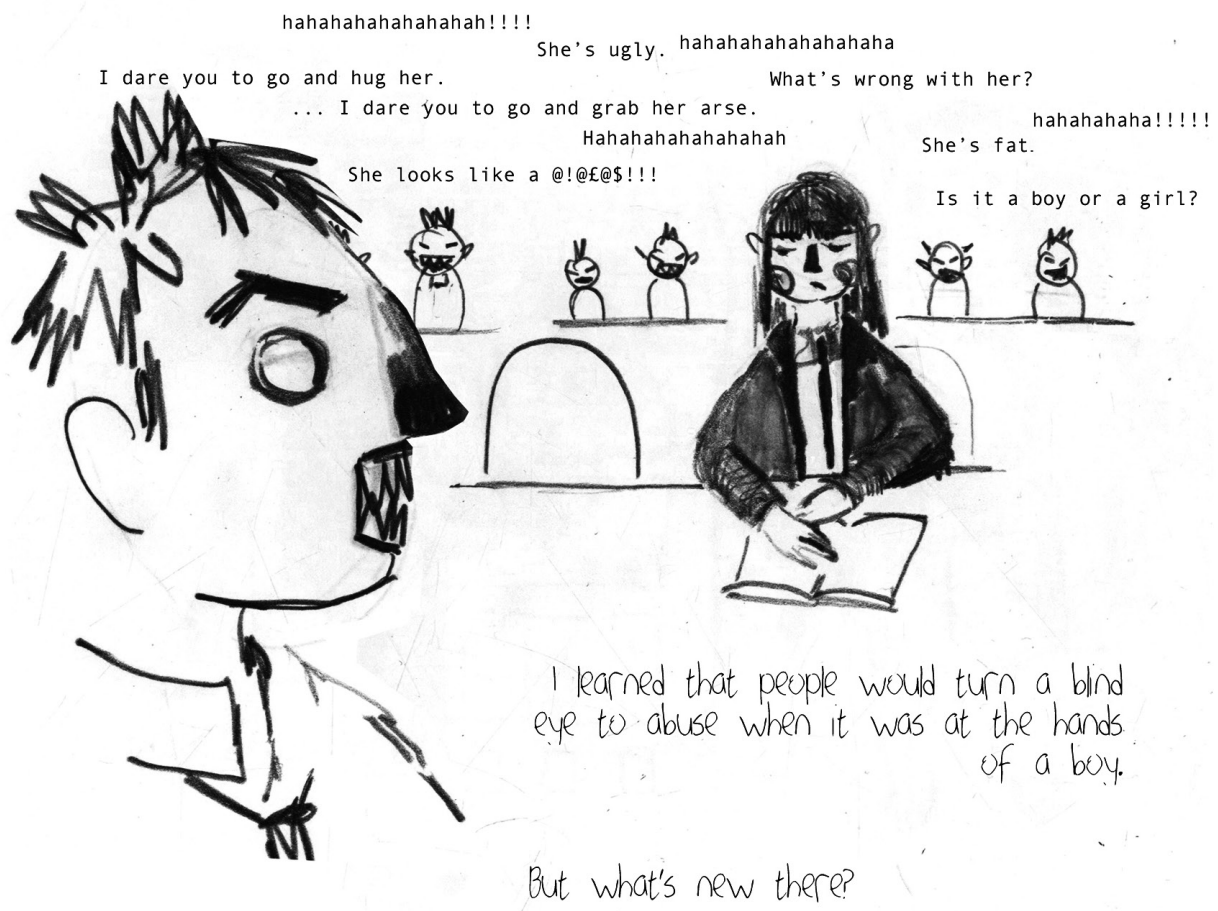

\section{Alice McCall}

I learned that people would turn a blind eye to abuse when it was at the hands of a boy. But what's new there? 


\section{\& OPENYOUR EYES $\$$}

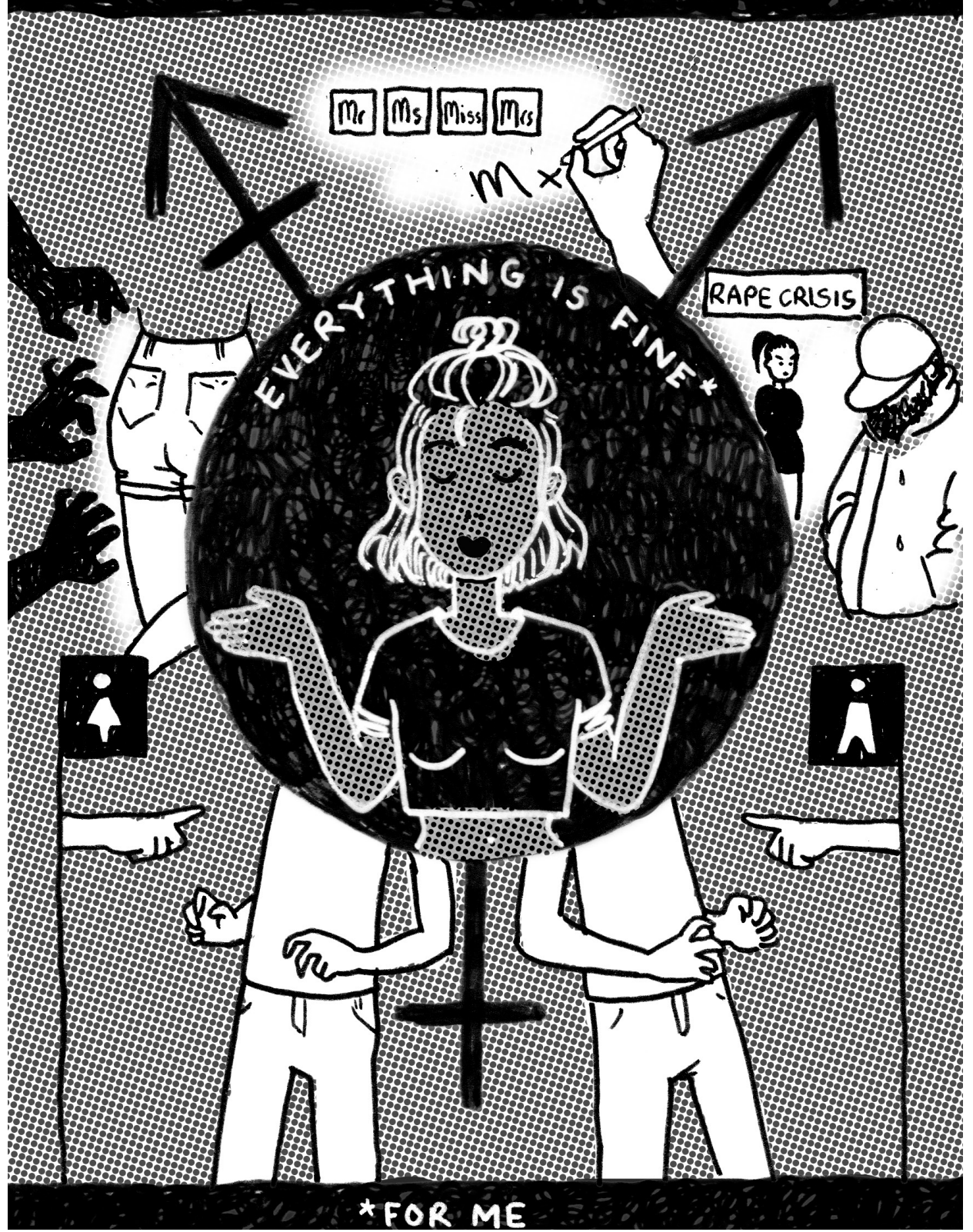

Han Deacon

Open your eyes 


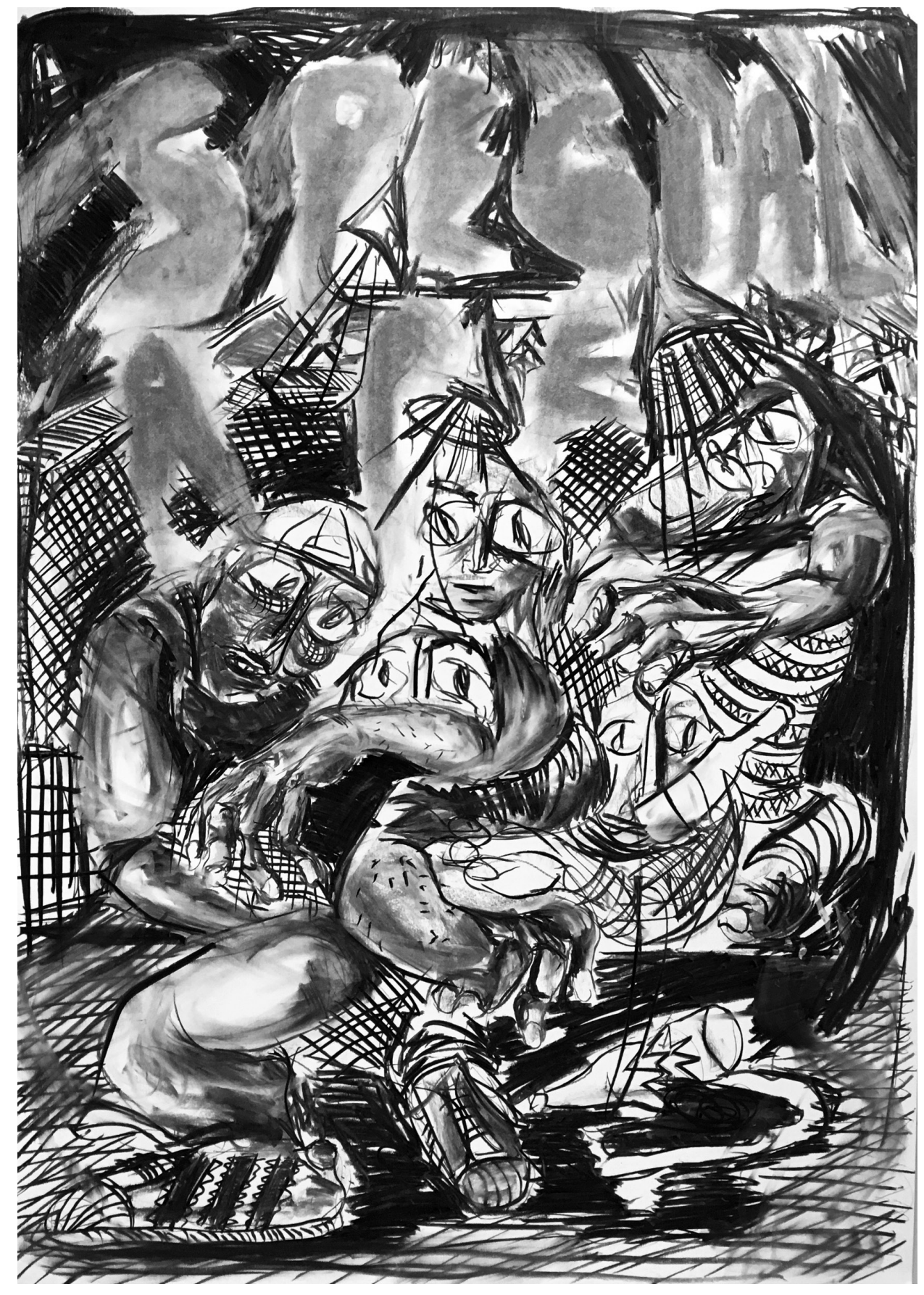

Harry Whitelock

Special Ape: Masculinity in the night club culture 

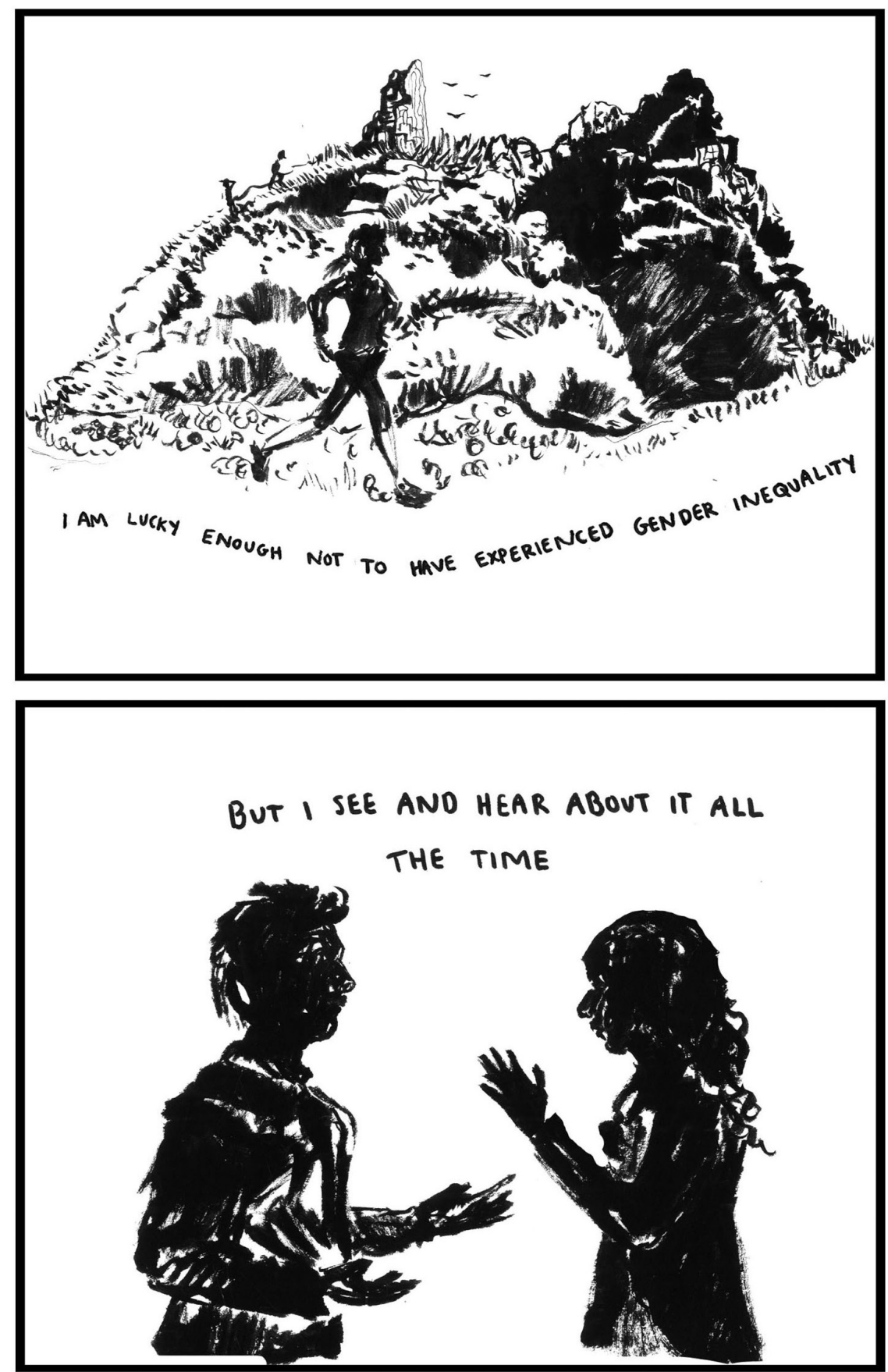

Madeline Pinkerton

Runners: "But I see and hear about it all the time" 

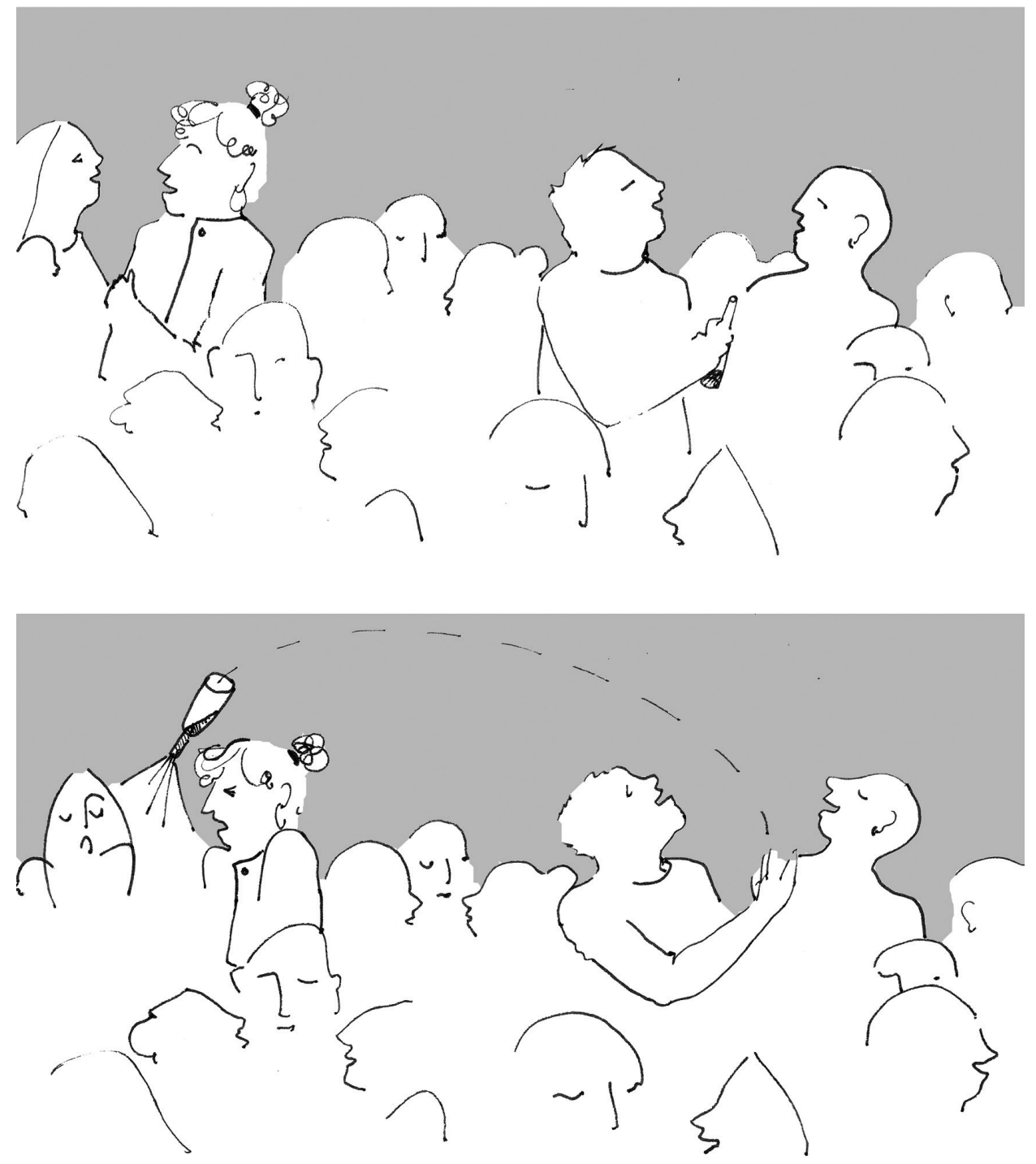

\section{Kathy Allnutt}

Potterrow bar "It's just a joke - don't get all serious on us" Throw the bottle, soak the girls (but blame them too...)

197 EqualBITE Perspectives from students 


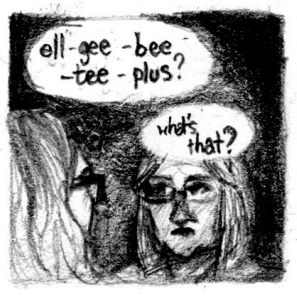

1 mean, yeah...

they are "just' microaggressions
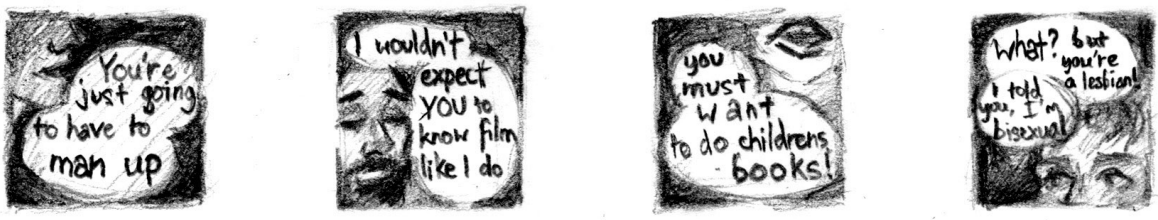

but you'll have to forgive me
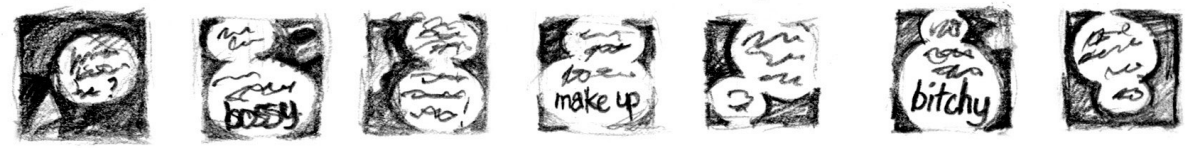

if my annoyance
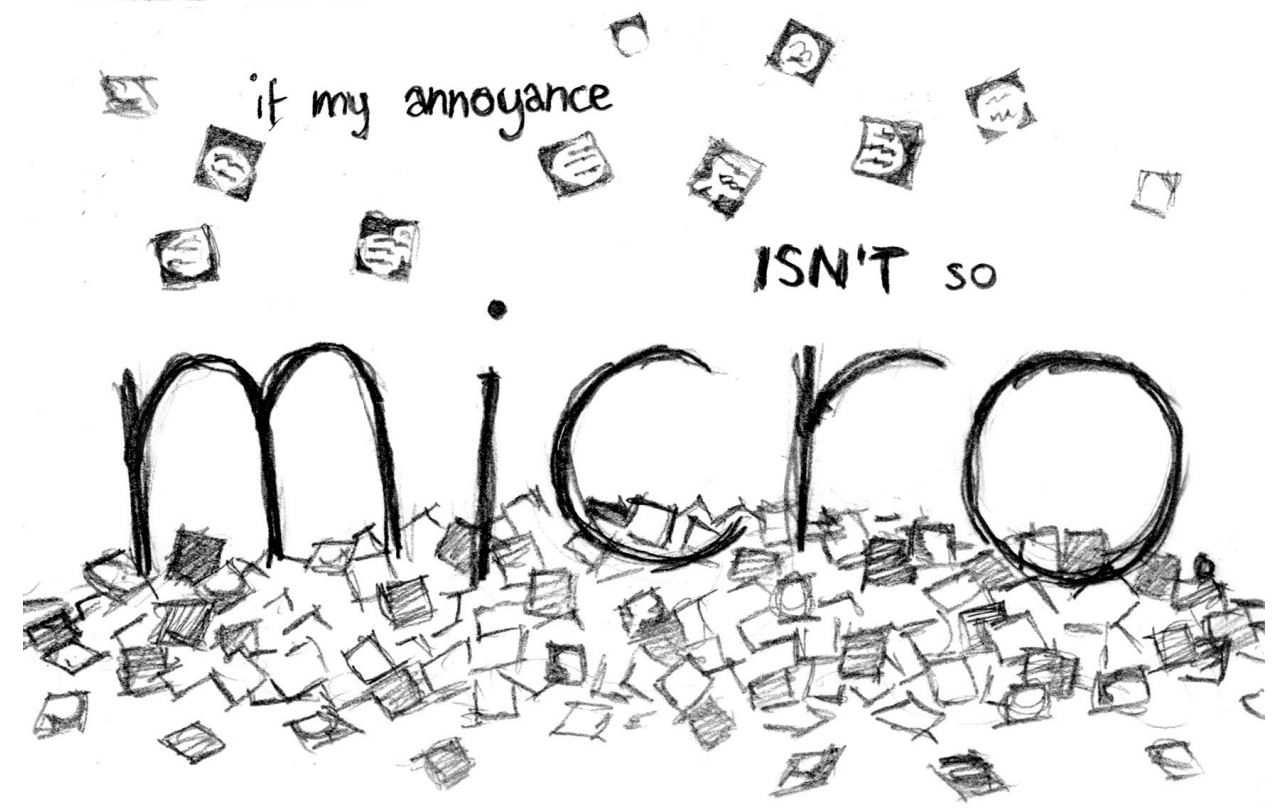

Rosie Hawtin

Microaggressions 


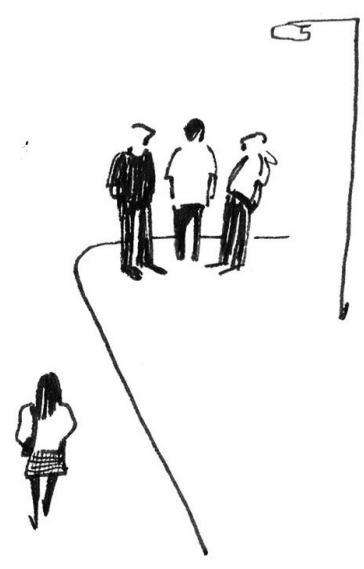

'just look down'

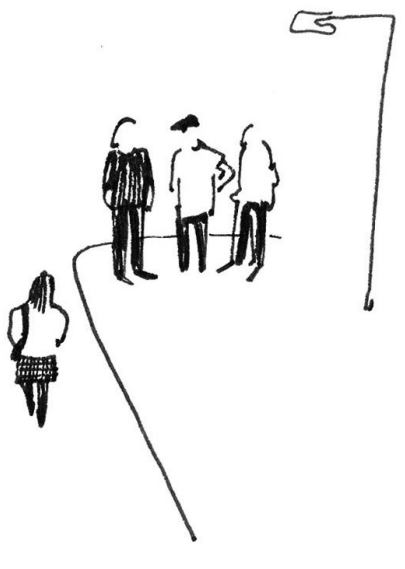

'don't attract attention'

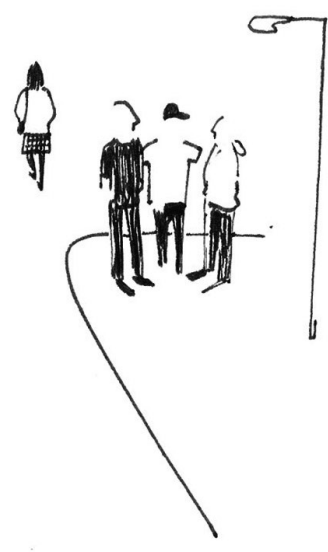

'and you'll be ok'

\section{Kathy Allnutt}

Street sexism 


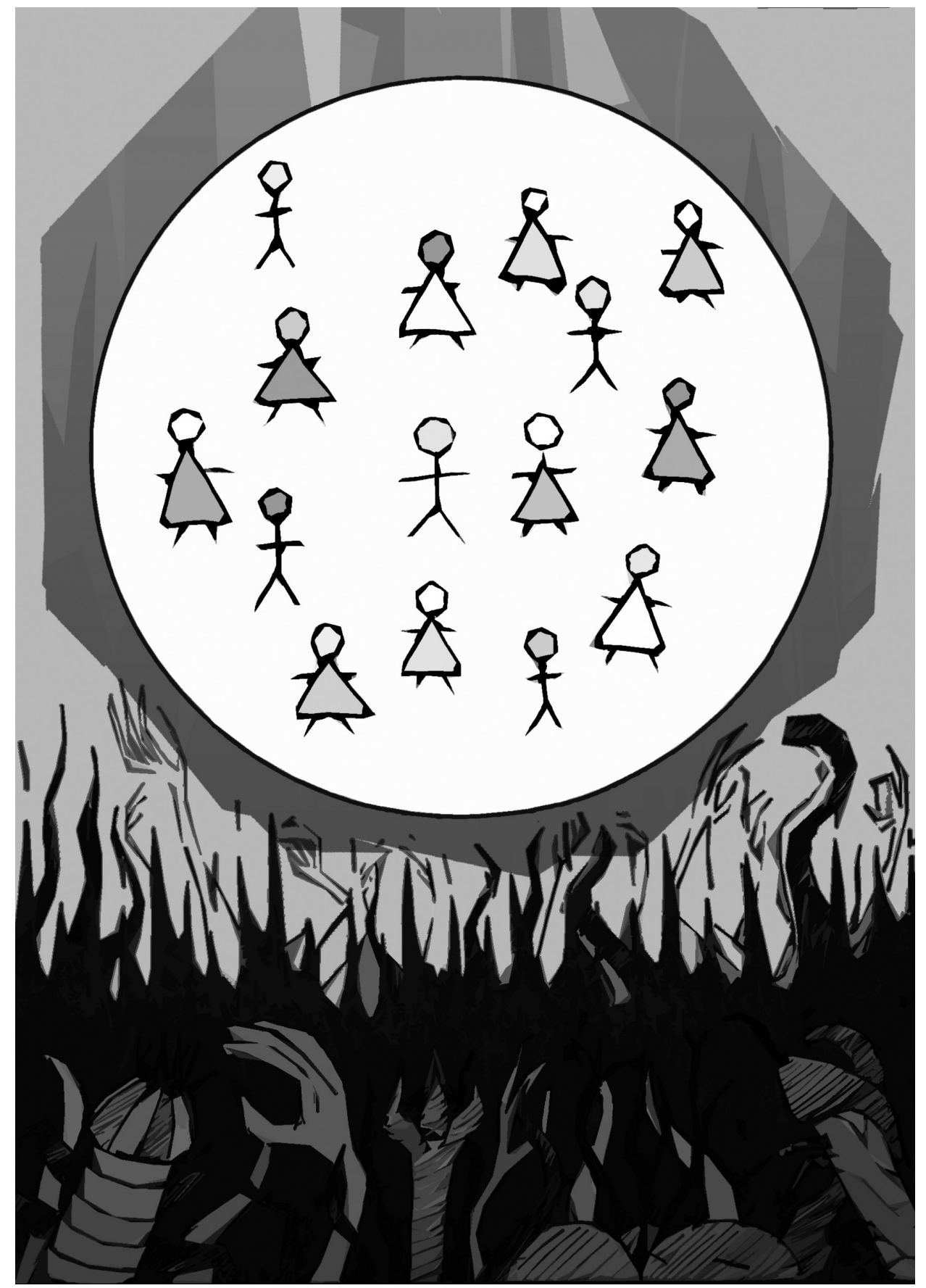

\section{Cael O'Sullivan}

Bubble of safety 


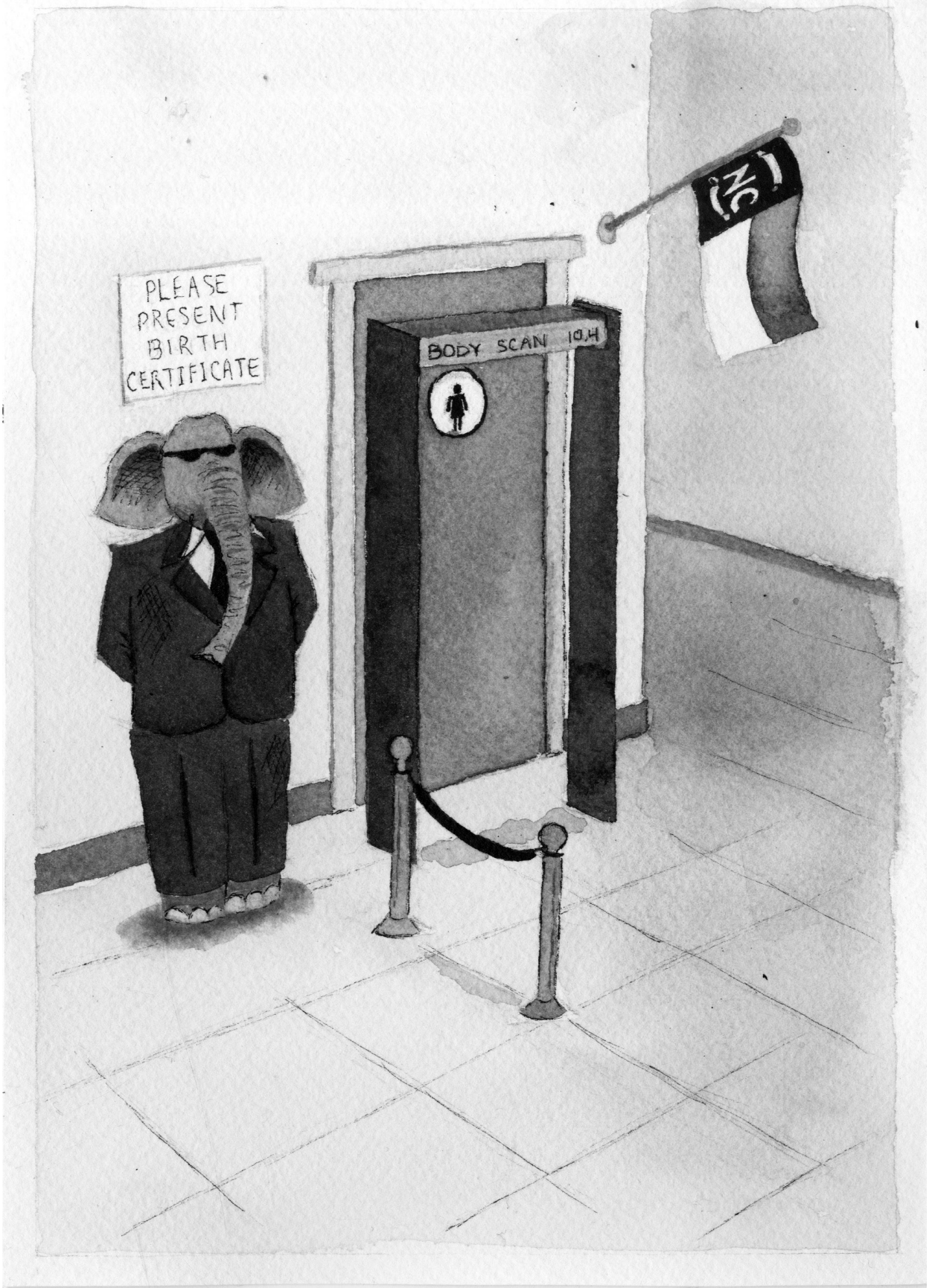

\section{Christine Meyer}

Elephant on guard 


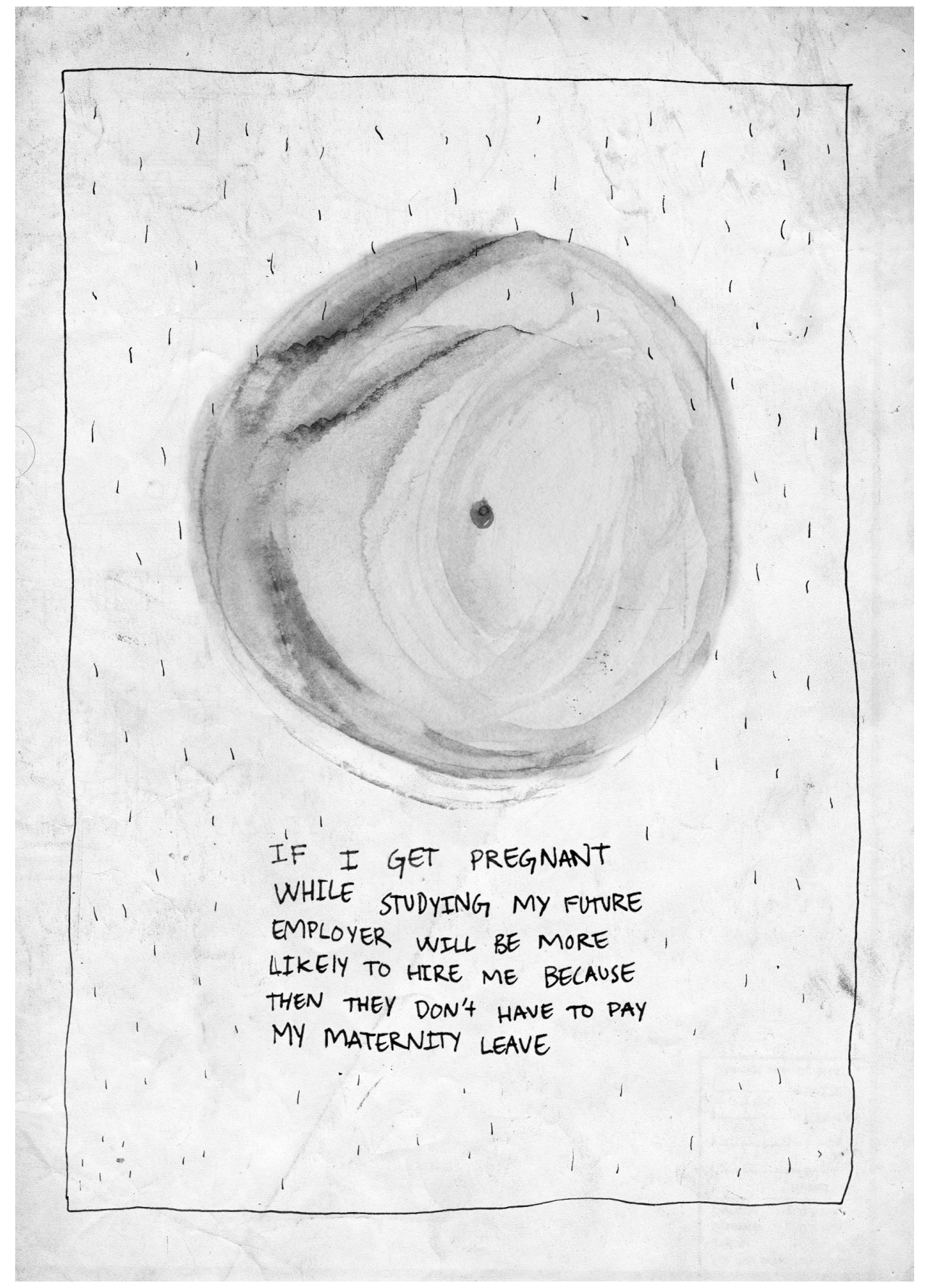

\section{Amalie Hjelm}

Pregnancy: a Scandinavian perspective 


\section{'Unapologetically Me' exhibition by University of Edinburgh students}

The editors were kindly invited to the Unapologetically Me photography exhibition at EUSA's Potterrow building, and spoke to Jenna Kelly the EUSA Vice President Services who co-organised it and explained how it came about.

In autumn 2016, Edinburgh University Students' Association and the Women's Liberation Group invited women and non-binary people on campus to participate in Unapologetically Me.

The project was a:

photography campaign designed to create an environment where we, and no one else, make the deliberate choices about how we present ourselves.

An organiser said:

All too often images of women and non-binary folk are subject to unrealistic sexist beauty standards, as well as racist and fat-phobic ideals. Our bodies are objectified and sexualised without our permission, and it feels like everyone gets a choice about how we are portrayed except us.

The group organised a series of photography workshops to teach people how to use cameras and editing software. Workshop participants produced a broad range of thoughtprovoking and inspiring self-portraits. The photographs were displayed at the Unapologetically Me exhibition in the Students' Association building in November, 2016.

We taught women and non-binary folk about the ins and outs of photography, and how to use a camera to make them look exactly the way THEY (and no one else) wanted themselves to look in a photo.

Several of the portraits and stories presented at this exhibition resonated with other issues that had emerged during the EqualBITE writing workshops. With kind permission of the organisers, we have included some of the student stories and portraits from the Unapologetically Me exhibition. 
The focus of the campaign was about creating your own image. Several of the young women responded to the pressures created by mixed messages of beauty standards and how this affected their body image and self-esteem:

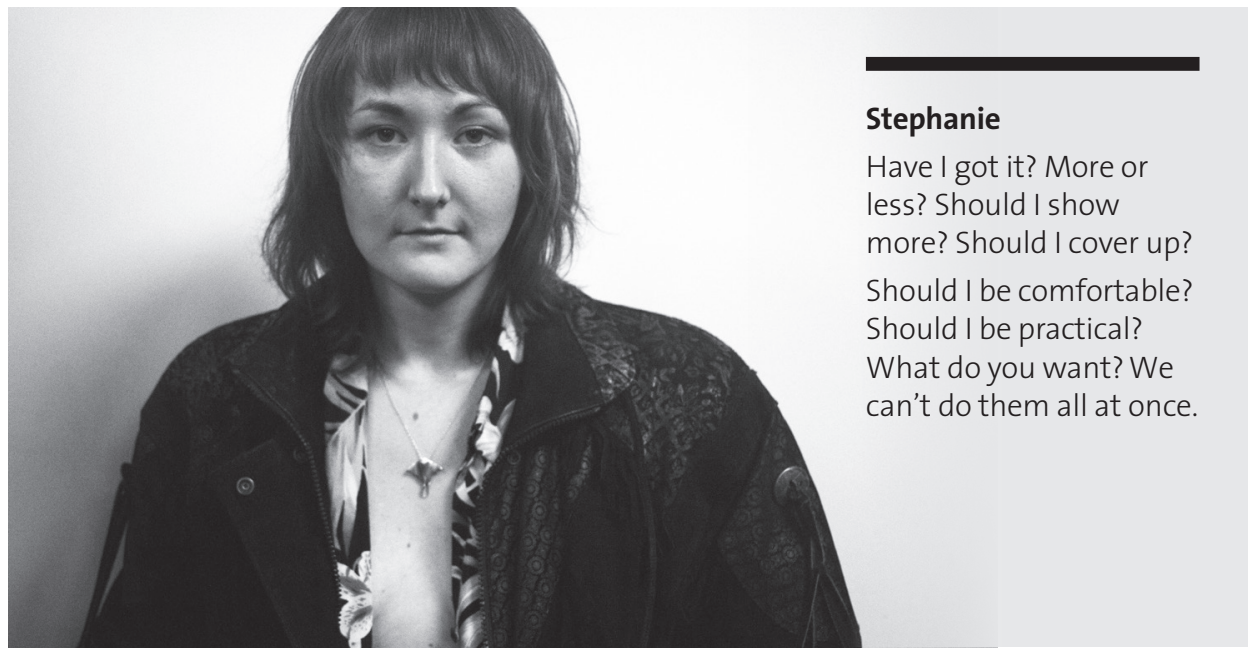

Julia shared her frustration:

I have always felt torn between the admiration of women boldly embracing their own bodies and imperfections (YES!) and trying to live up to what society (including me) has labelled as a perfect body. This makes me feel stuck in a vacuum between two ideals, failing on both fronts: not having the 'right' body as well as giving (more than) a damn that I don't. Being unapologetically me means accepting the balancing between two ideals and trying to move to simply taking care of myself.

\section{Julia}

In this photo I'm putting on body lotion, something I have been doing on a daily basis for as long as I can remember. I realised this is one of the few ways I take care of my body for the sake of taking care of it. Not wanting to change it, not neglecting it, not judging it.

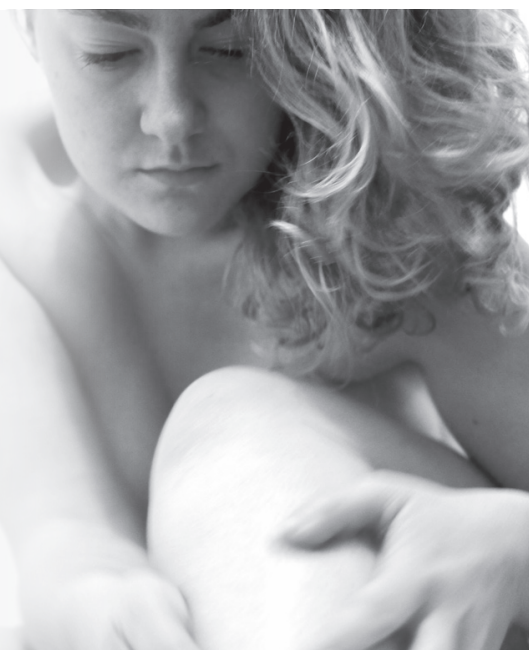


The focus on external appearance was particularly difficult for non-binary students.

Ester shared the dilemmas of bathroom choice:

\section{Ester}

Being myself often involves looking at the mirror in the morning and thinking whether I look feminine or masculine that day. I need to answer that question for myself because of bathrooms - whether I look feminine enough to go to the women's bathroom or masculine enough to get kicked out?

There were celebratory stories too, focusing on accepting yourself for who you are or ignoring the rules on what an 'acceptable' appearance should be.

Rumana said:

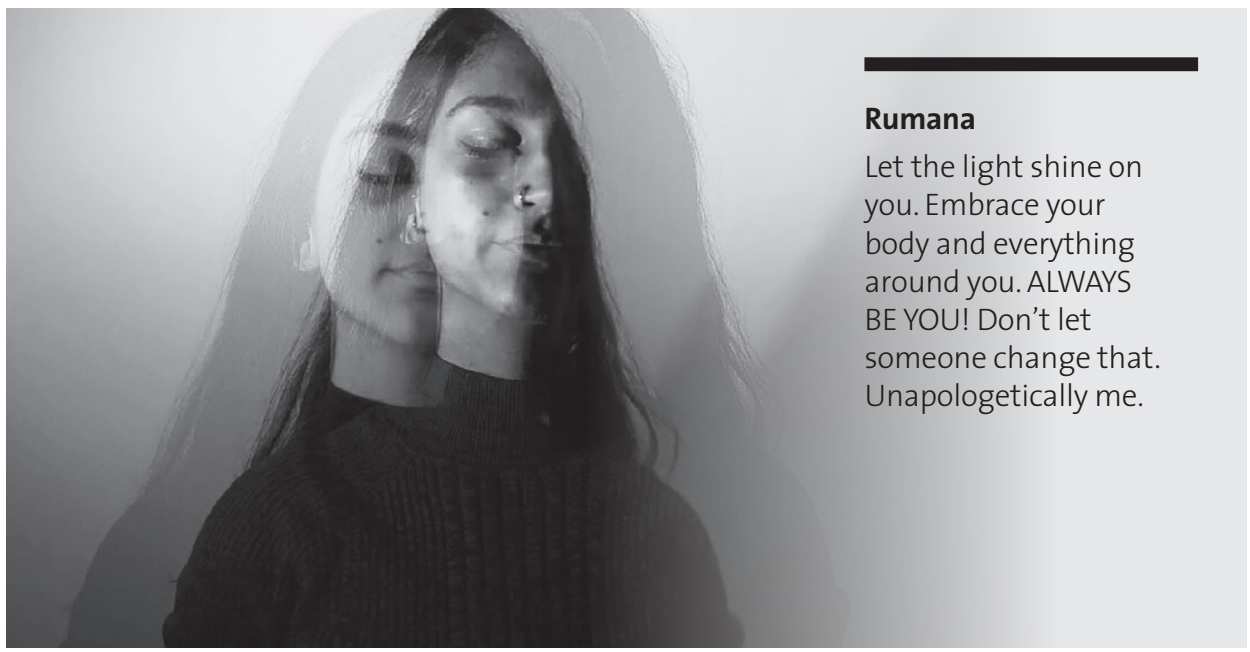


Amy described the importance of being free to express yourself as you want to.

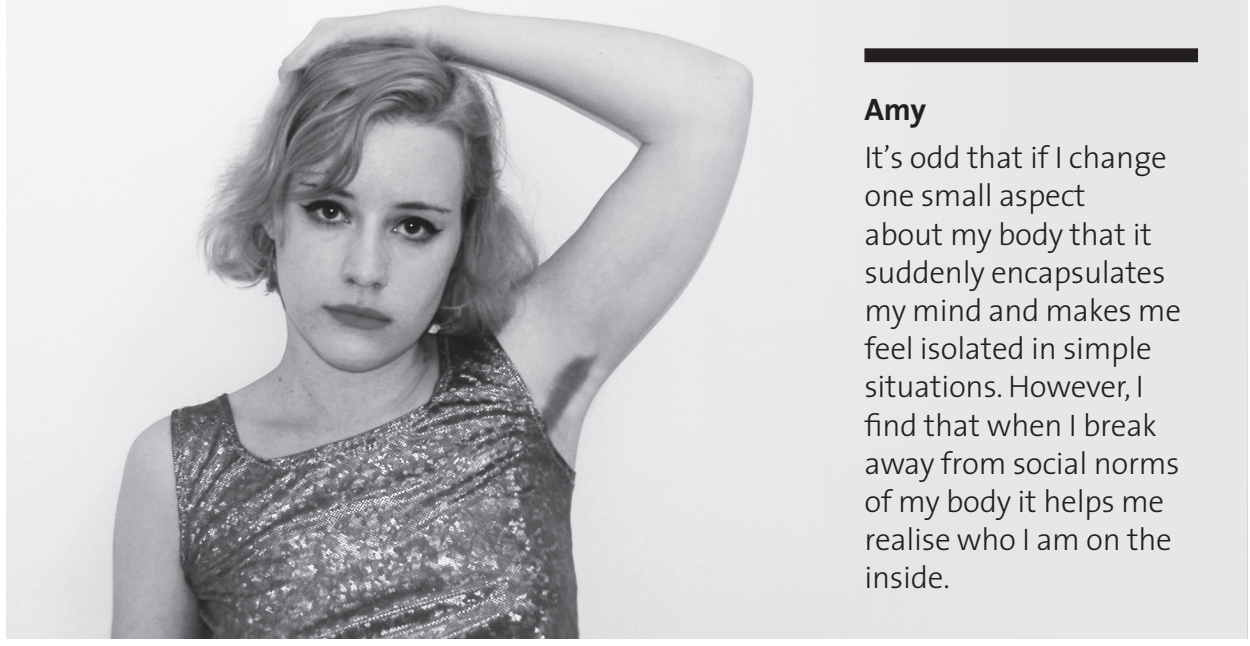

Lola said:

In my photo I wanted to be completely covered in make up because that's how I like it; I like to have giant eyeliner flicks and OTT spidery eyelashes pretty much every day regardless of what I'm doing. Lots of people say it's too much, that they prefer natural girls, or ask me why l'm trying so hard when I'm just at school or work. But for me it's not trying anything or even effort; I love my make-up routine as part of my day. At the last minute I decided to throw on lipstick too, because it struck me that women's magazines would probably strictly outlaw both at once and advise you only wear one or the other, to go with the concrete 'cleavage OR legs' rule.

Lola
When I really think about
it, if I constructed my face
for anyone other than
myself I'm pretty sure
I'd take the extensive
feedback I've been given
and tone it down, but I
definitely prefer the idea
that when I'm 78 I'll still
be walking about with a
super-exaggerated cat-eye
and a matte-lip look.

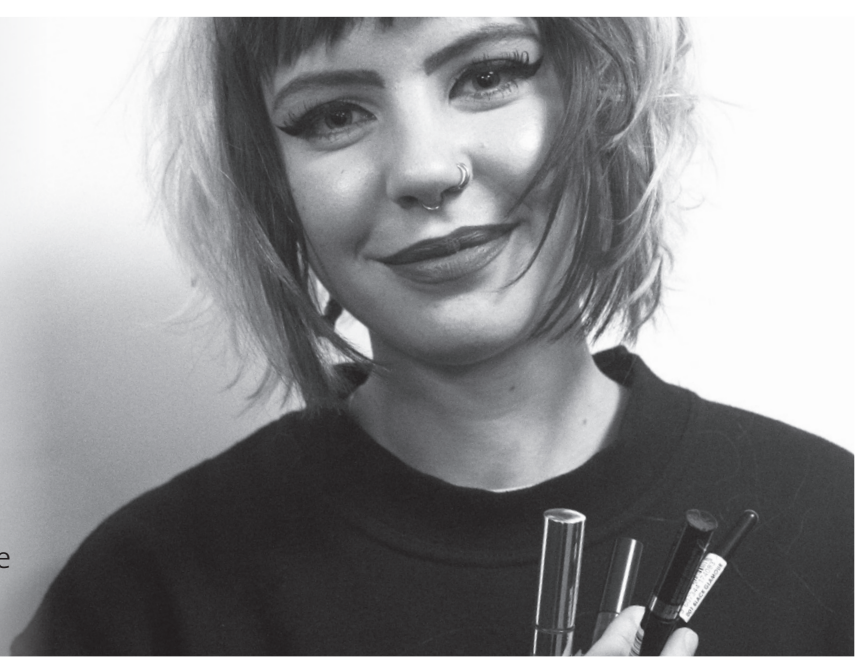


Students also shared their thoughts on the pressures to behave in a stereotypically feminine way - to be pleasant, smiling and approachable. This was also mentioned by older women taking part in the writing workshops for the book.

Eli said:

Women are often expected or forced to provide emotional labour in the form of smiling. How many times have you been asked to smile? At work, at school, in arguments, on the street, in a bar? It's a way to make us provide comfort and aesthetic pleasure even to those we may owe nothing, and a way to ensure women appear unthreatening. I suppose many of us would be better off if we tried being a bit more gentle. Yet it troubles me that for women, being serious so often is treated as being aggressive, and being cheerful is treated as naivety.

Eli

I've wasted too much time moulding myself to avoid this, forced into an unfair dichotomy where being taken seriously comes at the expense of being approachable and friendly. If we aren't smiling, we have a good reason to do so.

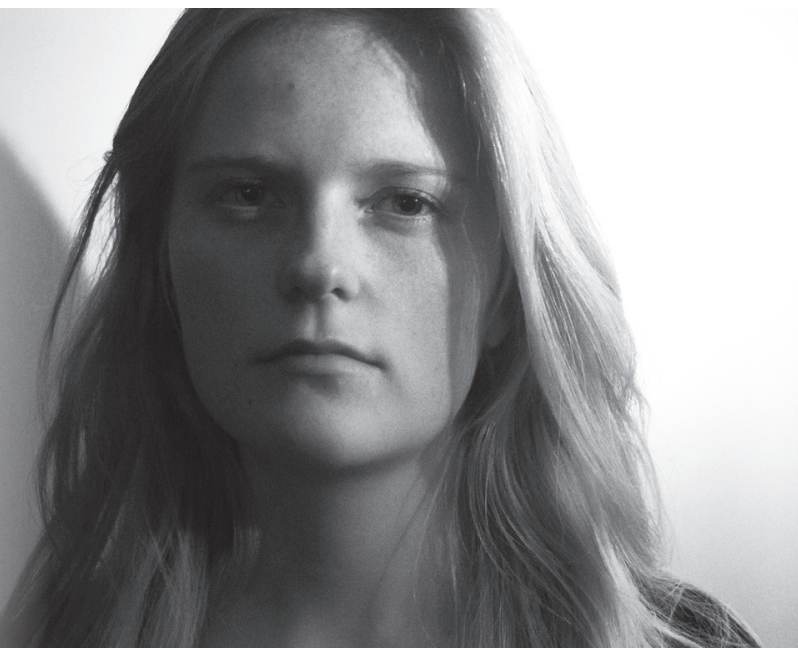


Bella shared her dream of a less stereotypical

approach to defining people.

I like the idea that our traits - intellect, mental faculties,

affection etc - rather than our gender, race and class

could define us. And I adore the idea that a woman

could be defined by her brain, and her brain alone.

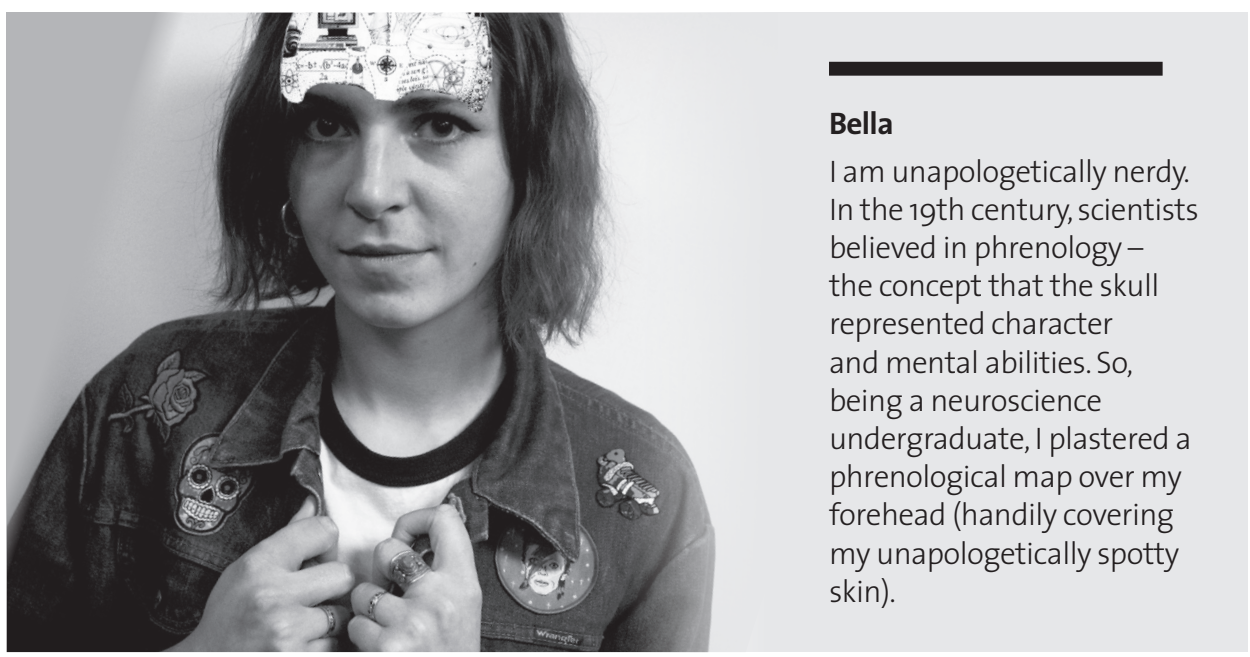

\section{Conclusions}

Academic colleagues may be familiar with the difficulties in coaxing students to participate in activities. "They just won't engage", our colleagues say, in tones ranging from sorrow to frustration. In this case, we had no expectation that students should engage: writing an article - even a short format recipe - is a big investment of time. We are very thankful to Chris, Danai, Zach and Hope and our other student authors for their valuable writing time. Even with the more concise format of writing a response to an online survey, we did not believe that students had any obligation to participate. What we decided to look for - and what we found in the end - were more flexible and creative options to record students' views.

We make no claims about how generalisable these views are. The views are fascinating because of the insights which they share and the questions which they raise. We hope that they are of interest to the reader, and that other teams of researchers will take up the challenge of extending the work.

A common theme running through the students' views is that of safety - in the sense of safety from harassment and assault, but also in the sense of safety to be oneself without criticism or resentment from others. Both senses of safety are necessary to thrive and flourish in university life. 